\title{
Influence of Aging Heat-Treatment on Damage Mechanisms of Particulate Reinforced Aluminium Matrix Composites
}

\author{
Irina Severin, Reader PhD \\ Politehnica University of Bucharest, \\ Splaiul Independentei, 313, cod 77206, Bucharest, Romania \\ E-mail: iseverin@pcnet.pcnet.ro; iseverin@amza.camis.pub.ro
}

\begin{abstract}
Recent active researches on the mechanisms of micro-damage and failure in particulate reinforced metal matrix composites (MMCs) have enhanced our understanding of the fundamental knowledge of lower ductility, one of the critical points of MMCs. Fracture mode analysis has been correlated with matrixreinforcement interface study. In this paper the fracture surface morphology of some $\mathrm{Al} / \mathrm{SiC}_{\mathrm{p}}$ composites processed in different states (hot-rolled and aged) has been examined using scanning electron microscopy. Detailed microstructural analysis has revealed a particular damage mode of composites containing low volume fraction of ceramic particles as compared to matrix alloy, respectively brittle on the macroscopic level and ductile on the microstructure level. Aging heat treatment has influenced damage mechanisms in matrix microstructure function and hardening precipitates distribution. As a result, in the case of under-aged and peak-aged composites failure is due to matrix ductile fracture, particle cracking and interface decohesion, while in the case of over-aged composites damage occurs by matrix inter-grain fracture and particle cracking. On the basis of microstructure analysis of particle reinforced composites, a damage model has been proposed.
\end{abstract}

\section{KEYWORDS}

composites, aging, microstructure.

\section{INTRODUCTION}

Although industrial-scale applications have been limited, metal matrix composites have been the focus of many researchers, being the objective of many cooperative research programmes.

The increasing interest in these advanced materials is justified, firstly, by the appearance on the market of cheaper reinforcements, available in the required quantities, and secondly, by elaboration and processing technologies which assure the improved compatibility of matrix-reinforcement couples and real possibilities for properties design and control.

Among the alloys used as composite matrix, aluminium alloys have a large scatter, the applications being restricted to medium temperature domain $\left(450^{\circ} \mathrm{C}\right)$. Taking into account the ratio between performance and cost, an increasing evolution in the next years is predicted for discontinuously reinforced composites type Al alloy / ceramic reinforcements (particles, whiskers, short fibres with low aspect ratio) $/ 1,2 /$, in particular for transport, sport and lejsure equipment fields.

Efficient use of the advantages offered by composites necessitates understanding and application of analytical and experimental methods for their performance characterisation $/ 3,4 /$. Composite properties depend on component characteristics and interface associated phenomena. For this reason, composites characterisation requires combined investigation methods, sensitive to crystalline lattice dynamics $15,6 /$, permitting the determination of 
properties, the explanation of complex behaviour, and the understanding of microstructure particularities $/ 7 /$.

At present, researchers are focusing, on one hand, on technological aspects related to property control, and on the other hand, explanation of independent or correlated mechanisms that lead to improved performance of composites $12 \%$. These complex problems are still unsolved, and are of great interest.

As compared to conventional alloys, discontinuously reinforced composites have presented both increased ultimate tensile strength, yield strength and elastic modulus, without much growth in density, and improved fatigue behaviour and wear strength. However, this improvement has been accompanied by a pronounced decrease in ductility. The very low ductility represents a critical point of discontinuously reinforced metal matrix composites, which also affects the processing possibilities. Researchers have explained low level ductility through the complex damage mechanisms and they have correlated fracture modes analysis with the interface study. Many research studies have been dedicated to composite damage, but authors' comments are not in agreement.

Correlation between damage modes and matrixreinforcement bonds at interface level have resulted from stress transfer efficiency, although it is not yet known how strong or weak these bonds have to be in order to ensure optimal performance. For example, a weak-bonded interface hinders fatigue fracture propagation $/ 8 /$, while a strong-bonded interface leads to a significant increase in the elastic modulus $/ 9,10 \%$.

The most important factors affecting composite damage mechanisms are:

- reinforcement characteristics - morphology, volume fraction, distribution in the matrix $/ 4,11-19$, etc./;

- elaboration and processing technology of the composite $/ 4,14,18,20,21 /$;

- chemical composition and final heat treatment of the composite $/ 4,8,11,22 \div 25 /$.

Process complexity developed in composites makes it difficult both to separate the contribution of the various factors to the damage and to identify a dominant mechanism leading to damage and fracture processes. References have revealed different damage mechanisms of discontinuously reinforced metal matrix composites, as follows:

$>$ ductile fracture of the matrix as a result of void nucleation, growth and coalescence $/ 10,20,26$ etc./;

$>$ interface decohesion as a result of void nucleation at interface level $/ 15,16,27,28 /$;

$>$ ductile fracture of the matrix in the immediate vicinity of reinforcements (in the non-deformable zones) $/ 7,15,29,30 /$;

$>$ reinforcement fracture followed by crack propagation in the matrix $/ 8,13,17,23,30-32 /$.

These mechanisms have been proposed on the basis either of the morphology analysis of tensile tested samples, or the more complex study of in-situ tensile testing.

The present study has focused on the damage mode analysis of particle reinforced aluminium composites $\left(6063 \mathrm{Al} / \mathrm{SiC}_{\mathrm{p}}\right.$ ) processed in different states (hot-rolled and aged) through scanning electron microscopy and finally, a damage model for particle reinforced composites has been proposed.

\section{EXPERIMENTAL PROCEDURE AND RESULTS}

Among different heat treatments applied to aluminium matrix composites, the paper has focused on the final heat treatment of solution, quenching and aging treatment, developed in order to assure the best potential performance of the composite. The experimental procedure has been carried out on a composite consisting of a deformable and hardenable matrix alloy reinforced with ceramic particles subjected previously to thermo-mechanical processing.

Composite samples of $6063 \mathrm{Al}$ alloy matrix (chemical composition: $0.7 \% \mathrm{Mg}, 0.4 \% \mathrm{Si}$, rest $\mathrm{Al}$ ) reinforced with $\mathrm{SiC}$ particles (mean size $10-14 \mu \mathrm{m}$, volume fraction $5 \%$ and $10 \%$ ), were elaborated through Vortex technique, cast in steel-moulds and then hotrolled and T6 aged, as reported in detail elsewhere $/ 4 /$.

The hot-rolling parameters were: deformation temperature $-300^{\circ} \mathrm{C}$ and $350^{\circ} \mathrm{C}$; intermediate degree of deformation $-8 \%, 14 \%$ and $20 \%$; total deformation degree $-47 \%$. The samples were cast as $\varnothing 10 \times 100$ 
(mm) cylinders and then, square - rolled at $\square 4(\mathrm{~mm})$ with different thermo-mechanical parameters.

In order to establish the influence of aging heat treatment on composite mechanical characteristics, the hot-rolling parameters were chosen at their optimal values, which were determined with the aid of a mathematical model based on a centre composed orthogonal experimental program, presented in detail in 14,33/. These parameters are as follows: deformation temperature $-300^{\circ} \mathrm{C}$, intermediate deformation degree $14 \%$, intermediate heating duration $-15 \mathrm{~min}$.

As-rolled samples were solutionized at the temperature of $525^{\circ} \mathrm{C}$ for 40 minutes and then quenched in lukewarm water at $50^{\circ} \mathrm{C}$. The solution temperature and duration were chosen in accordance with the recommendation for the matrix alloy $\left(500-530^{\circ} \mathrm{C}, 10-\right.$ $60 \mathrm{~min}$ ). The aging treatment was carried out at $175^{\circ} \mathrm{C}$ temperature for a varying duration of $1-7$ hours, followed by cooling in air.

Tensile samples were then machined and tested. The mechanical properties were determined as the mean of three tensile testings and the hardness and microhardness using five measurements. The tensile testing results are given in Fig. 1. The Brinell hardness HB 2,5/ $31,5 / 30$ and Vickers microhardness $\mu \mathrm{HV}_{50}$ were determined and the results are given in Fig. 2. Precipitation duration for the examined composites was determined. Mechanical characteristics and precipitation efficiency (calculated on the basis of hardness increase) for the composite and the unreinforced matrix are compared in Table 1. The influence of the thermomechanical cycle on peak-aged composite characteristics is compared in Table 2.

Tensile tested samples (Fig. 3) were examined on the both sides of the fracture surface with the aid of scanning electron microscopy. Some microfractographic photos were chosen to reveal particular aspects of the examined composite fracture mode (Fig. $4 \div 6$ ).

It was noticeable that aging heat treatment has influenced damage mechanisms in function of matrix microstructure and hardening precipitates distribution. As a result, in the case of under-aged (Fig. 4) and peakaged (Fig. 5) composites, failure is due to matrix ductile fracture, particle cracking and interface decohesion, while in the case of over-aged composites (Fig. 6) damage occurs by matrix inter-grain fracture and particle cracking (Fig. 7). Even if particle distribution in the as-cast composite has been quite uniform (Fig. 8), thermo-mechanical processing leads to particle orientation (Fig. 9) along the matrix yield direction (hotrolling direction), as reported in detail elsewhere $/ 7 \%$. Bands of particles resulting during the hot rolling processing have been susceptible to damage in the overaged composite (Fig. 7).

On the basis of microstructure analysis of particle reinforced composites, a damage model has been

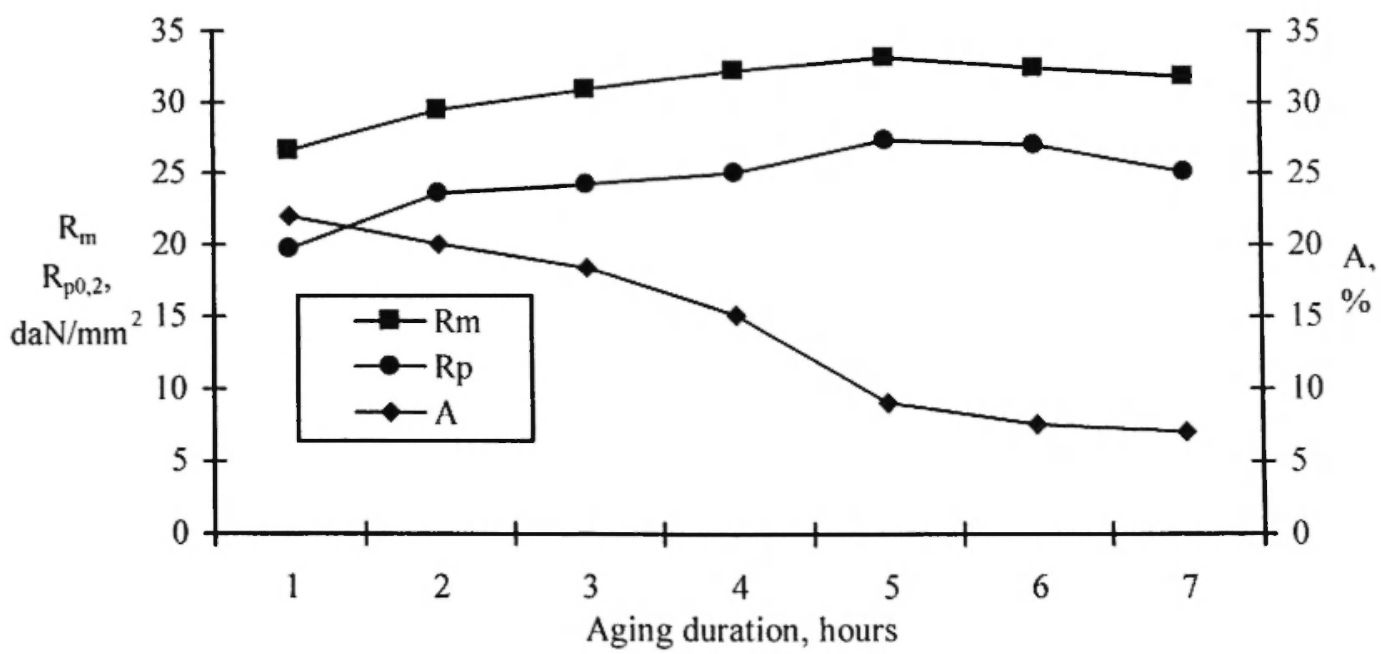

Fig. 1: Influence of ageing duration on the mechanical characteristics.

(Legend: $R_{m}$-ultimate tensile strength, $R_{p(1)}$ - yield strength, $A$-elongation to fracture) 


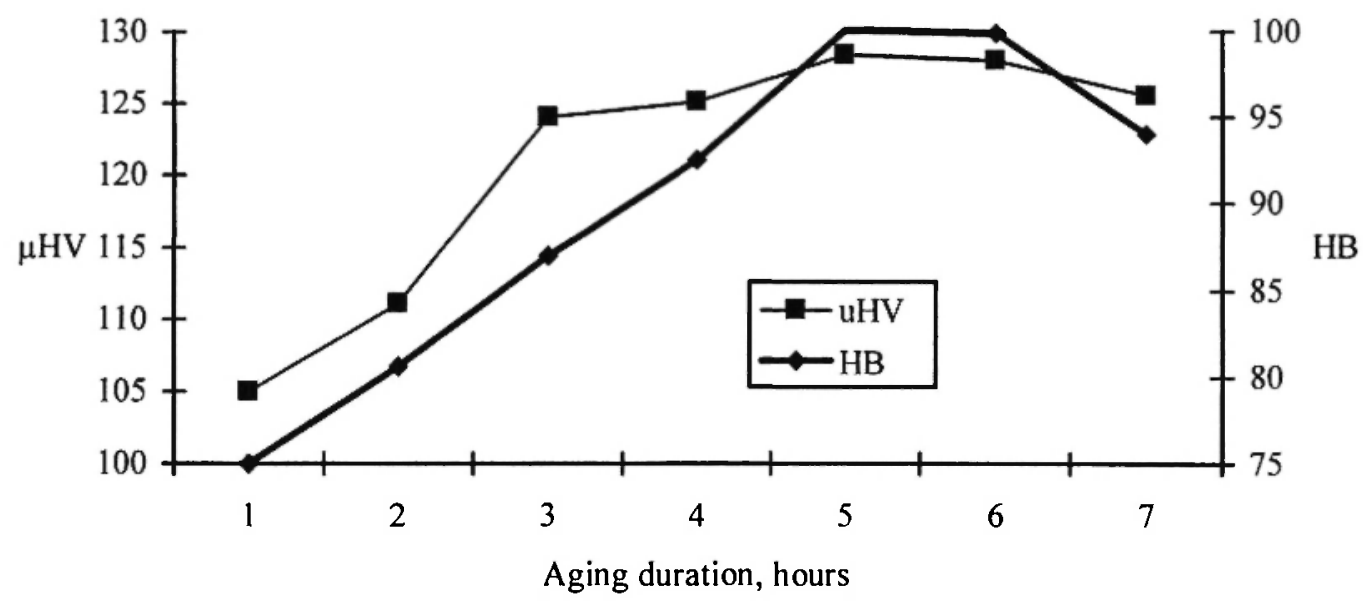

Fig. 2: Influence of ageing duration on hardness.

(Legend: $\mu H V_{50}$ - Vickers microhardness, testing load 50gf; $H B$ 2,5/31,5/30 - Brinell hardness, ball indenter diameter2, $5 \mathrm{~mm}$, testing load 31,5 daN, testing duration 30s)

Table 1

Comparison between composite and matrix alloy characteristics* and precipitation hardening efficiency

\begin{tabular}{|c|c|c|c|c|c|}
\hline Characteristic & $\mathrm{R}_{\mathrm{m}}$ & $\mathrm{R}_{\mathrm{p} 0.2}$ & $\mathrm{HB}$ & $\mathrm{A}_{5}$ & $\begin{array}{c}\text { Precipitation } \\
\text { efficiency } \\
\%\end{array}$ \\
\hline Material & $\mathrm{N} / \mathrm{mm}^{2}$ & $\mathrm{~N} / \mathrm{mm}^{2}$ & & $\%$ & 292 \\
\hline $\begin{array}{c}\text { Composite } \\
6063 \mathrm{Al} / 5 \% \mathrm{SiC}_{\mathrm{p}}\end{array}$ & 241 & 214 & 73 & 12 & \\
\hline
\end{tabular}

Legend: $R_{m}$ - ultimate tensile strength, $R_{p 0,2}$ - yield strength, $A$ - elongation to fracture, $H B$ - Brinell hardness

Table 2

Influence of hot-rolling processing cycle on the mechanical characteristics of the peak-aged $6063 \mathrm{Al} / 5 \% \mathrm{SiC}_{\mathrm{p}}$ composite

\begin{tabular}{|c|c|c|c|c|c|}
\hline $\begin{array}{c}\text { Deformation } \\
\text { temperature } \\
{ }^{\circ} \mathrm{C}\end{array}$ & $\begin{array}{c}\text { Deformation } \\
\text { cycle* }\end{array}$ & $\begin{array}{c}R_{m} \\
\mathrm{~N} / \mathrm{mm}^{2}\end{array}$ & $\begin{array}{c}R_{\mathrm{p} 0,2} \\
\mathrm{~N} / \mathrm{mm}^{2} \\
\end{array}$ & $\begin{array}{l}A \\
\% \\
\end{array}$ & $\begin{array}{c}\mathrm{HB} \\
2,5 / 31,5 / 30\end{array}$ \\
\hline 300 & $\begin{array}{c}3 / 3 / 2 / 1 \\
3 / 2 / 2 / 2 \\
3 / 3 / 3\end{array}$ & $\begin{array}{l}322 \\
334 \\
286 \\
\end{array}$ & $\begin{array}{l}280 \\
288 \\
267 \\
\end{array}$ & $\begin{array}{c}8,5 \\
7,5 \\
6 \\
\end{array}$ & $\begin{array}{c}94 \\
101 \\
92 \\
\end{array}$ \\
\hline 350 & $\begin{array}{c}3 / 3 / 2 / 1 \\
3 / 2 / 2 / 2 \\
3 / 3 / 3\end{array}$ & $\begin{array}{l}251 \\
262 \\
246\end{array}$ & $\begin{array}{l}228 \\
248 \\
241 \\
\end{array}$ & $\begin{array}{c}11,2 \\
10,2 \\
7,5\end{array}$ & $\begin{array}{l}85,2 \\
90,1 \\
88,3 \\
\end{array}$ \\
\hline
\end{tabular}

${ }^{*}$ number of passes (1- deformation degree $8 \% ; 2-14 \% ; 3-20 \%$ ) / heating to the deformation temperature for $15 \mathrm{~min} /$ number of passes / heating for $15 \mathrm{~min}$... etc. 


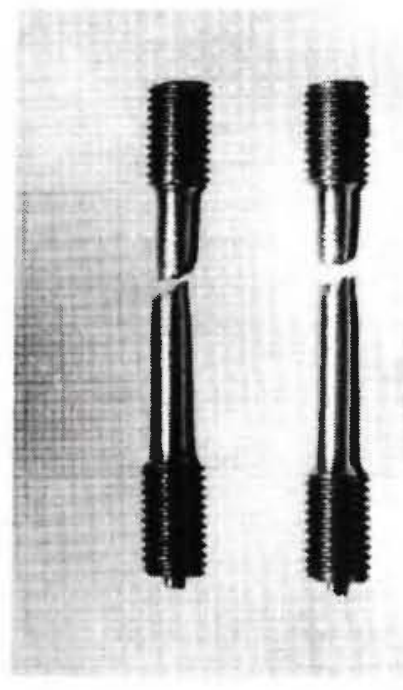

(a) under-aged (ageing duration 2 hours)

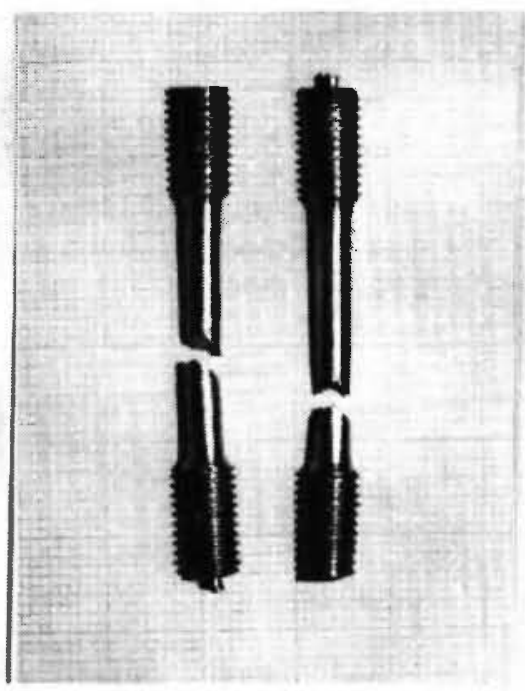

(b) peak-aged (ageing duration 5 hours)

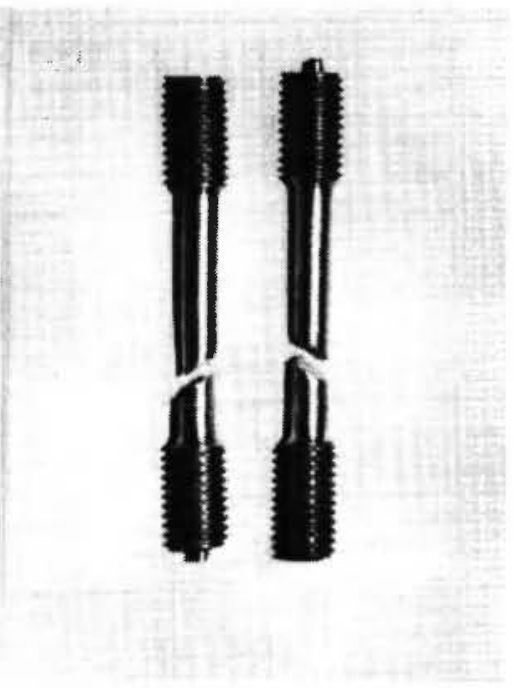

(c) over-aged (ageing duration 7 hours)

Fig. 3: Tensile tested samples of $6063 \mathrm{Al} / \mathrm{SiC}_{\mathrm{p}}$ hot-rolled and aged.

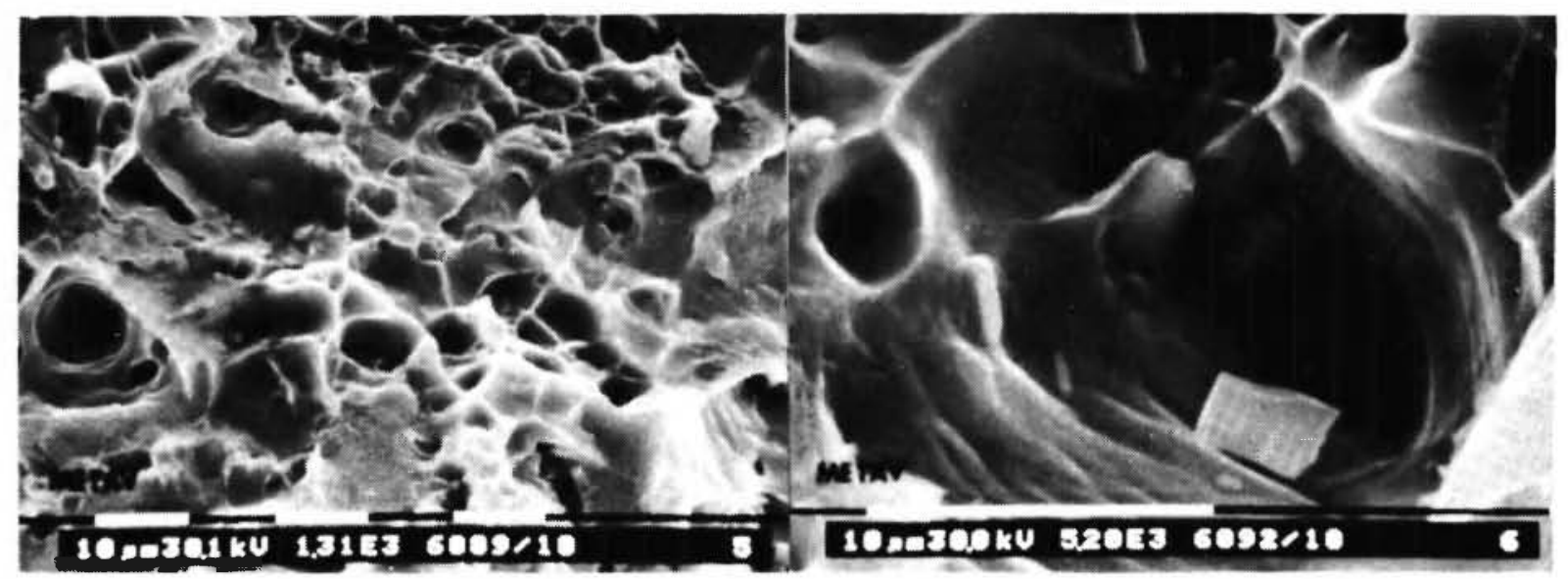

(a)

(b)

Fig. 4: Surface morphology of the hot-rolled and under-aged composite ( $a, b$ - different magnifications).

proposed (Fig. 10).

\section{PRECIPITATION KINETICS IN 6063AI / $\mathrm{SiC}_{\mathrm{P}}$ COMPOSITES}

It is known that the artificial aging treatment (T6) of aluminium alloys develops at temperatures ranging from $140-180^{\circ} \mathrm{C}$, for an aging duration of $6-10$ hours. In particular, the $\mathrm{Al}-\mathrm{Mg}-\mathrm{Si}$ alloy, coded $6063 \mathrm{Al}$, is aged at a temperature of $170-180^{\circ} \mathrm{C}$, for an aging duration of 610 hours

Following the heat treatment procedure, the mechanical characteristics and the hardness of the 


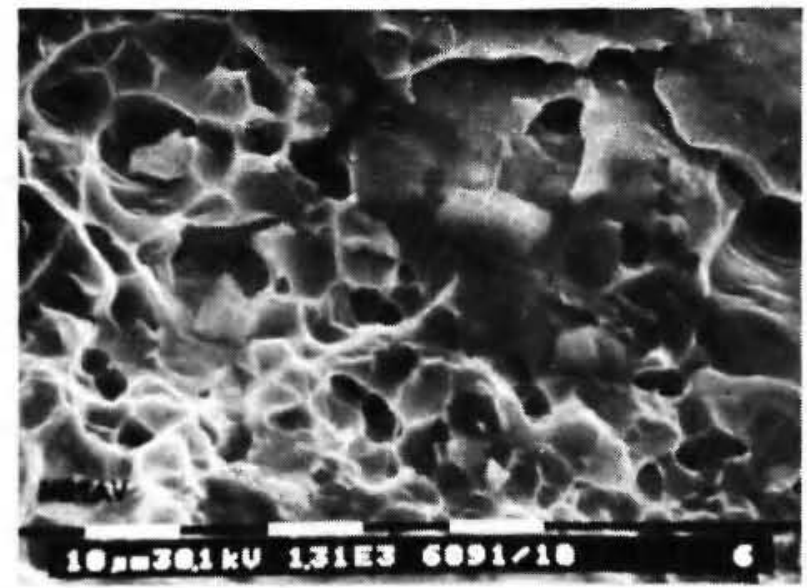

Fig. 5: Surface morphology of the hot-rolled and peakaged composite. investigated composite $-6063 \mathrm{Al} / \mathrm{SiC}_{\mathrm{p}}(5 \%, 10-14 \mu \mathrm{m})$ - have the variation depicted in Figures 1, 2.

During composite solidification, intermetallic compounds - in the studied composite $\mathrm{Mg}_{2} \mathrm{Si}$ segregated, frequently, at grain boundaries and sometimes as isolated precipitates. Dissolution of Chinese script $\mathrm{Mg}_{2} \mathrm{Si}$ precipitates (segregated at grain boundaries) would be probably more difficult than isolated ones, but this phenomenon is not critical since the solution treatment is carried out for a longer time than the minimum required for complete homogenisation.

When applying artificial aging treatment, the precipitation process starts in solid solution crystals

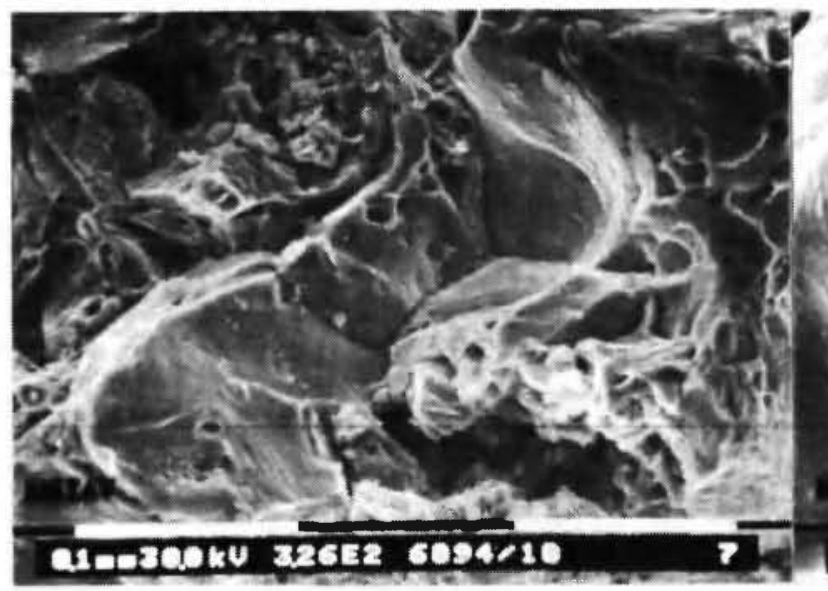

(a)

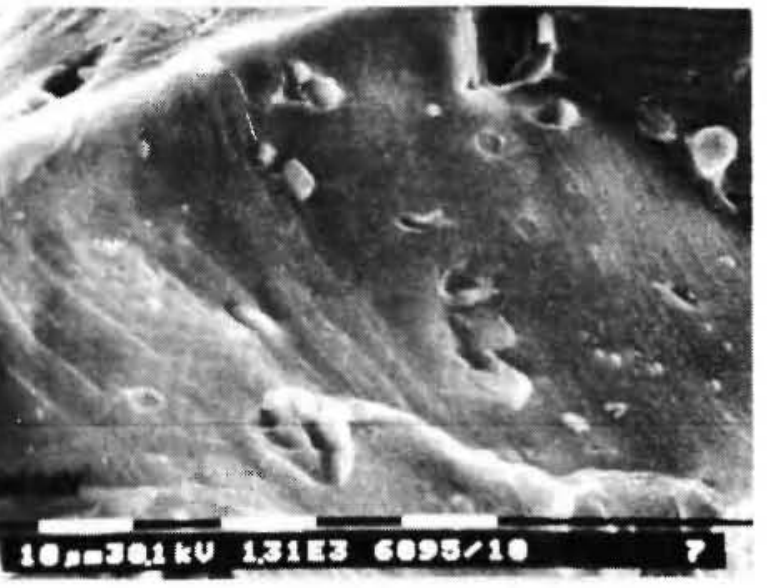

(b)

Fig. 6: Surface morphology of the hot-rolled and over-aged composite ( $a, b-$ different magnifications).

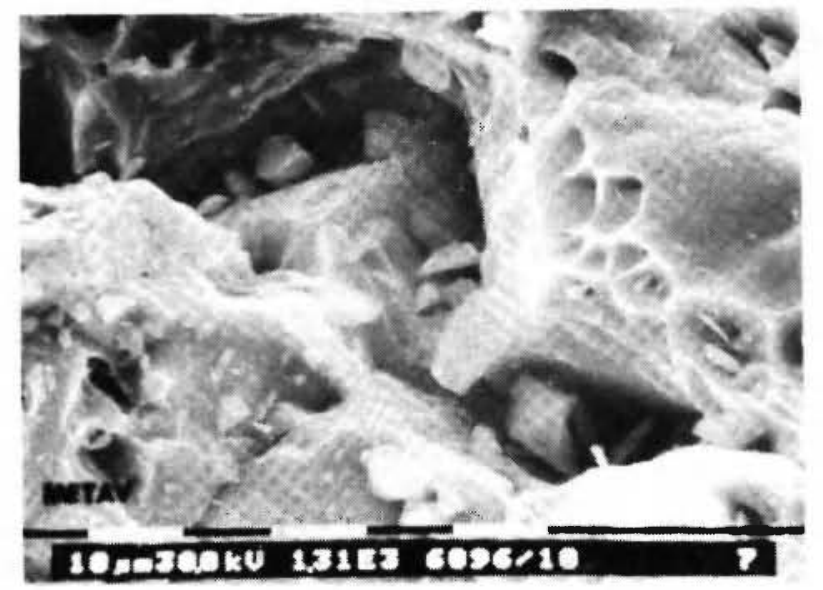

Fig. 7: Propagation of crack along the reinforcements distributed as bands in the over-aged composite. saturated in alloying components. At the same time, the tensile characteristics and hardness increase reaching a maximum value; then, if the aging duration is prolonged, the characteristics begin to decrease. Elongation to fracture is maximum in as-quenched state, decreasing continuously while aging duration increases.

This behaviour may be noticed for the studied composite. The aging duration corresponding to the maximum strength and hardness values resulted 5 hours, that is slowly lower than the matrix aging duration (610 hours). Considering other authors' experimental results, the acceleration tendency of precipitation at composites aging $/ 34-37 /$ is mentioned more frequently than the deceleration tendency $138,39 /$, as compared with similar unreinforced alloys. 


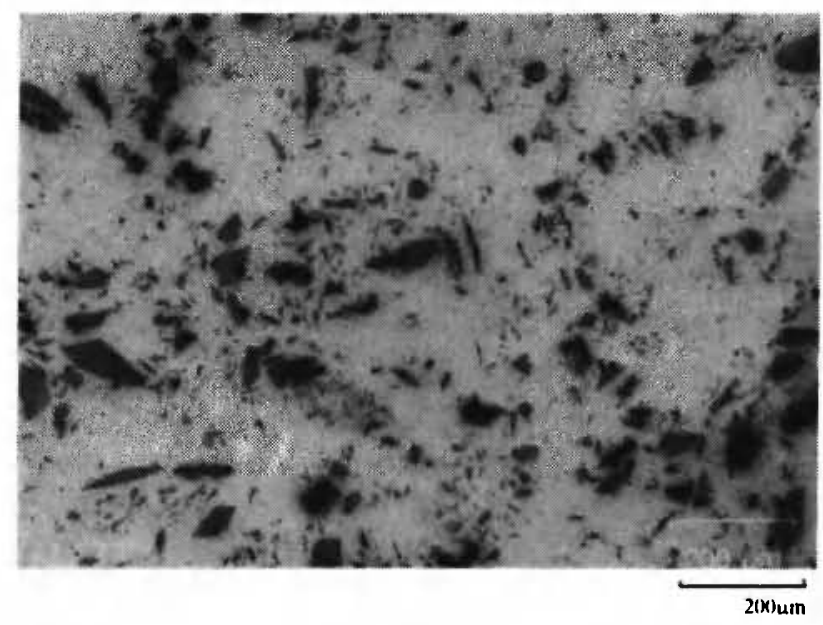

Fig. 8: Optical microstructure of as-cast $6063 \mathrm{Al} /$ $5 \% \mathrm{SiC}_{\mathrm{p}}$ composite.

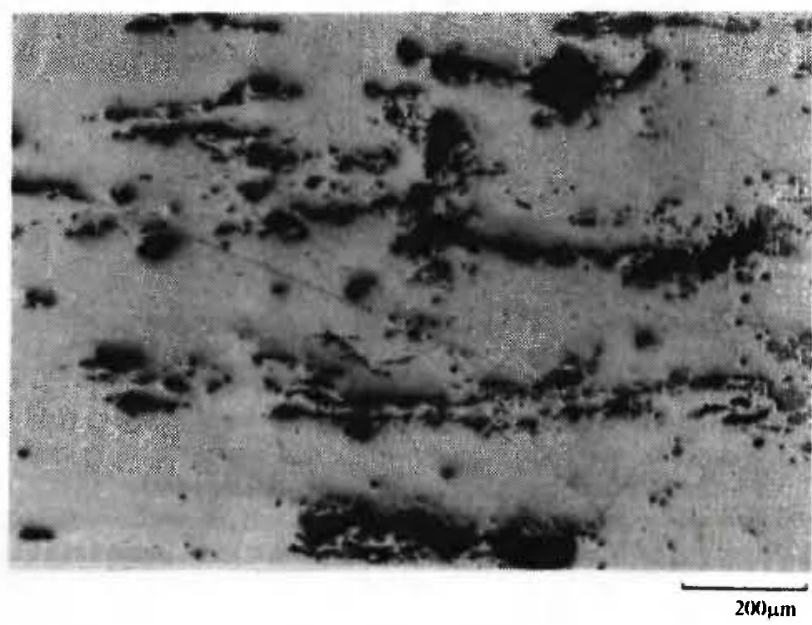

Fig. 9: Optical microstructure of as-cast, hot-rolled and peak-aged $6063 \mathrm{Al} / 5 \% \mathrm{SIC}_{\mathrm{p}}$ composite.

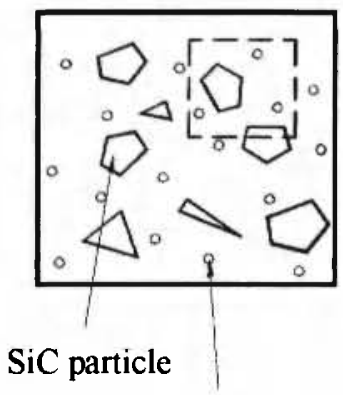

\section{$\mathrm{Mg}_{2}$ Si precipitates} and fine particles

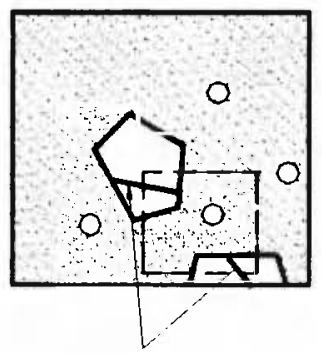

particles may fracture, crack may propagate along interface

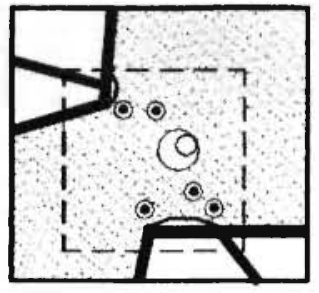

voids nucleation and growth

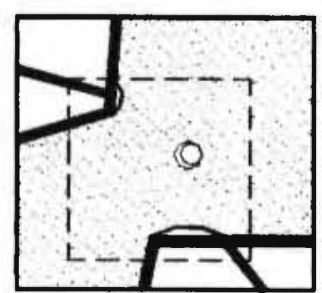

fine particles lead to microvoids appearance

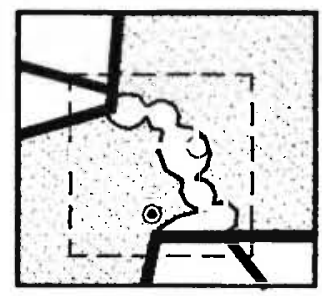

voids coalescencc

Fig. 10: Damage model of composites containing low volume fraction of particles.

Precipitation acceleration of discontinuously reinforced composites may be explained by diffusion considerations and enhanced nucleation. As is known, the coefficients of thermal expansion of composite components are very different (being in the ratio $5: 1$ ) leading to an increased dislocation density in the composite that increases diffusion and promotes nucleation, thus accelerating precipitation.

This dislocation density depends on the reinforcement volume fraction and the aspect ratio. In the case of high aspect ratio reinforcements, the dislocation density is more increased and, as a result, 
the composite aging answer would be more accelerated than in the case of particulate reinforced composites. Moreover, the reinforcement distribution affects the precipitation, a uniform distribution determining a more homogeneous precipitation. It may be noticed that the higher the dislocation density, the finer the precipitation.

Salvo \& Suerry $/ 40 /$ noticed that, in the case of $6061 \mathrm{Al} / \mathrm{SiC}_{\mathrm{p}}$ composites, the acceleration of agehardening kinetics takes place only beyond a critical temperature corresponding to the domain of heterogeneous precipitation. Below this temperature, for which nucleation occurs homogeneously, the hardening behaviour of the composites seems to be identical to that of the unreinforced matrix.

Another remark depicted by the experimental results is the larger domain covered by the maximum tensile strength and hardness in the $6063 \mathrm{Al} / \mathrm{SiC}_{\mathrm{p}}$ composite case as compared the matrix. This behaviour may be explained by the longer duration required for $\mathrm{Mg}_{2} \mathrm{Si}$ precipitates coarsening in the composite, where the precipitates are finer.

Comparing the composite characteristics following a complete processing (thermo-mechanical processing and age-hardening heat treatment) and the matrix corespondent ones (Table 1), a smaller efficiency of age hardening may be noticed in the composite case. The aging efficiency was defined as the maximum hardness increase due to precipitation. One explanation for this aspect is the smaller volume fraction of matrix in the composites compared to unreinforced matrix, which should lead to efficiency proportional to the matrix volume fraction. The problem should not be treated simplistically, since hardness is influenced not only by the state of precipitation, but by the overall microstructure $/ 40 \%$.

The mechanical characteristics of the examined composite appear enhanced over those of the matrix alloy. The ultimate tensile strength, the yield strength and the hardness are significant higher in the case of the composite.

At the same time, an important increase in composite ductility is noticed, as compared to previous results when the composite was in as-cast state or it was shaped without optimising the technological parameters and the processing route $133 /$. The ductility improvement is an important result since low ductility levels represent one of the composite's drawbacks. Using the optimised processing route followed by solution, quenching and aging treatment, the ductility of $6063 \mathrm{Al} / \mathrm{SiC}_{\mathrm{p}}$ composite increased from $0,5 \%$ in as-cast state, $1-4 \%$ in hot-processed state (inadequately processing route) to $7.5-9 \%$ after optimised hot-rolling processing and age-hardening treatment.

The thermomechanical processing cycle and the applied technological parameters have influenced the composite aging response and the final mechanical characteristics, too, as shown in Table 2. As reported elsewhere $133 /$, the optimum hot-rolling parameters were: the deformation temperature, equal to the recrystallisation one $-300^{\circ} \mathrm{C}$; the deformation degree $14 \%$. Taking into account the mechanical characteristics of the hot-rolled and peak-aged composites, one may notice that a deformation temperature equal to the recrystallisation one leads to better composite characteristics. On the other hand, the deformation degree influence is more complex. It seems that a lower deformation degree leads to better properties, even if the processing technology has been non-economic. A degree of higher deformation may determine possible micro-damage associated to any particle agglomerations and finally, negative effects on the mechanical characteristics. For this reason, it is strongly recommended to determine the optimised deformation degree using an experimental procedure in order to obtain the desired characteristics.

\section{FRACTOGRAPHIC ANALYSIS OF COMPOSITES DAMAGE MODE}

The macroscopic aspect of the composite tensile tested samples is presented in Figure 3. On the basis of tensile testing results and SEM examination of both sample fracture surfaces, it has been appreciated that the examined composites presented a quasi-brittle damage mode, an observation in agreement with other studies. One may notice that $6063 \mathrm{Al} / \mathrm{SiC}_{\mathrm{p}}$ composites have a particular damage mode as compared to the unreinforced matrix, respectively brittle at the macroscopic level and ductile at the microscopic one.

Moreover, the fracture model proposed by Ghosh 
/41, pp. $409 /$ for the case of the alloys containing dispersed precipitates may be extended for discontinuously reinforced composites, too. The model has considered that fracture owns to microvoid nucleation on inclusions and precipitates in the material, their deformation, growth and coalescence in the maximum shear stresses plane.

Aging heat treatment has influenced composite damage mechanisms in function of microstructure and hardening precipitate distribution (in the examined case - $\mathrm{Mg}_{2} \mathrm{Si}$ ), as follows. The composite processed in optimised hot-rolling conditions, then quenched and aged for a two-hour aging duration (under-aged) presents high ductility (elongation to fracture $18 \%$ - Fig. 1) and the fracture surface morphology is characterised by either deep or fine dimples (Fig. 4). In some dimples, isolated ceramic fragments are present (Fig. 4b). Deep dimples are accompanied by sliding lines that may be associated to the significant distortion of matrix plastic yielding in the particle vicinity. In the under-aged composite, around the fractured reinforcements, hardened zones have developed, hindering coalescence of cracks belonging to adjacent particles.

The increase in aging duration is accompanied by microvoid nucleation on $\mathrm{Mg}_{2} \mathrm{Si}$ precipitates that start to grow resulting in deep dimples associated with particles together with fine equiaxial dimples (Fig. 5). In the peak-aged state (aging duration - 5 hours), elongation to fracture decreases at $9 \%$ (Fig. 1). If the matrix has contained some extended particle agglomerations aligned during hot-rolling, composite damage may be determined by matrix fracture and rapid propagation of the crack along particles and interfacial zones.

In the over-aged composite, the damage mode is inter-grain fracture favoured by $\mathrm{Mg}_{2} \mathrm{Si}$ precipitates agglomeration at grain boundaries (Fig. 6). When the aging duration increases over the peak value (aging duration -7 hours), ductility decreases (elongation to fracture $7 \%$ - Fig. 1). This may be explained by the effect of stresses in the matrix, associated both with cracks belonging to fractured particles (Fig. 7) and microvoids, characteristic to over-aged microstructure, formed in the precipitates' vicinity and propagated along grain boundaries (Fig. 6).

Even if as-cast composites have presented a nearly uniform distribution of reinforcements (Fig. 8), fine particles are very susceptible to agglomeration and, to some extent, this tendency may be noticed. The microstructure of the hot-rolled composite has presented bands of particles resulting from particle redistribution and orientation along the rolling direction (Fig. 9). These bands are not affected by aging heat treatment and the banded microstructure has increased damage susceptibility. The effect is more pronounced in the case of over-aged composites, particle bands promoting rapid fracture propagation.

On the basis of morphological examination of composite tensile tested samples, it was shown that, as regards composite processing technology and technological parameters, damage is dominated by matrix ductile fracture, accompanied by ceramic phase fracture and / or interface decohesion.

A damage model has been synthesised in Figure 10. As already described, high sized particles crack both during thermo-mechanical processing and first stages of tensile testing. Matrix plastic yielding is hindered by the presence of reinforcement, so in matrix ligaments among close particles, triaxial stresses become very high, exceeding maximum shear stress. As a consequence, in matrix, in the particles' close proximity, microvoids appear. During testing, the increase of the stress determines the rapid growth of microvoids, then the coalescence of voids.

Reinforcement geometry influences stress distribution in the matrix. Fine particles and ceramic fragments which result from composite plastic deformation have a higher tendency to decohere at interface level than to fracture. The presented model is valid for the case of discontinuously reinforced composites containing low volume fractions of reinforcements $(<10 \%)$, when damage is dominated by ductile matrix failure, together with reinforcement fracture and / or interface failure.

\section{CONCLUSION}

A better knowledge of the behaviour of particular composites under age-hardening treatment is required to predict the overall characteristics of the composites and thus to promote their use in structural applications.

The complete and optimised processing followed by 
final heat treatment - solution, quenching and agehardening - of the $6063 \mathrm{Al} / \mathrm{SiC}_{\mathrm{p}}$ composite has led to improved mechanical properties as compared the unreinforced matrix alloy. The hot-rolled and peak-aged composite has a satisfactory ductility.

Comparing the age-hardening behaviour of the composite and the corespondent matrix alloy, the following has been noticed:

* the aging duration of 5 hours, lower than the matrix one, that revealed the precipitation acceleration in the composite;

* the larger domain for the maximum tensile strength covering the aging duration;

* the reduced efficiency of age-hardening in the composite;

In the case of the examined composites, the optimised hot-rolling cycle leading to maximum mechanical characteristics after aging treatment has been: deformation temperature $-300^{\circ} \mathrm{C}$, the intermediate degree of deformation $-14 \%$.

On the basis of tensile testing results and SEM examination of the both samples fracture surfaces, it has been appreciated that the examined composites presented a quasi-brittle damage mode, respectively brittle at macroscopic level and ductile at microscopic one. Aging heat treatment has influenced damage mechanisms in function of matrix microstructure and hardening precipitate distribution. As a result, in the case of under-aged and peak-aged composites, failure is due to matrix ductile fracture, particle cracking and interface decohesion, while in the case of over-aged composites damage occurs by matrix inter-grain fracture and particle cracking. Banded microstructure resulted during thermo-mechanical processing is not affected by heat treatment, but increases composite damage susceptibility, in particular in the over-aged state.

A damage model valid for the case of composites containing low volume fractions of reinforcements $(<10 \%)$ has been proposed. High size particles crack and, at the same time, in matrix ligaments among close particles, triaxial stresses exceed maximum shear stress.

\section{REFERENCES}

1. C. Peel, J. Robertson and A. Tarrant. Have metal matrix composites proved their worth. Material World, 1, 8-9 (1995).

2. R. F. Gibson. Principles of composite materials mechanics. McGraw-Hill, Inc., New York (1994).

3. G. Zgură and I. Severin. Metal matrix composites characterisation through advanced investigation techniques. BREN, Bucharest (1999), ISBN 97399065-4-0.

4. I. Severin. Studies and researches on plastic deformation of aluminium matrix composites. Doctoral thesis, Politehnica University of Bucharest, Romania (1997).

5. I. Severin and M. Salvia. Internal friction in $\mathrm{Al} /$ $\mathrm{SiC}_{\mathrm{p}}$ composites. Met. New Mat. Res., VI (1), 8-21 (1998).

6. I. Severin, A. Voicu, C. Bunescu and S. Vasile. Characterisation of MMCs behaviour during plastic deformation by acoustic emission. Proc. Euromat'97, 21-23 April, Maastricht, Holland, 183-186 (1997).

7. 1. Severin, G. Zgură and I. D. Marinescu. Microstructure evolution in $6063 / \mathrm{SiC}_{\mathrm{p}}$ composites. J. Sci. Eng. Comp. Mat., 7 (4), 315-322 (1998).

8. M. J. Hadianfard, J.C. Healy and J.-W. Mai. Fracture toughness of discontinuously reinforced aluminium 6061 matrix composites. J. Mat. Sci., 28, 6217-6221 (1993).

9. D. L. McDanels. Analysis of stress-strain, fracture and ductility behaviour of aluminium matrix composites containing discontinuous silicon carbide reinforcement. Met. Trans., 16A (6), 11051115 (1985).

10. H. Ribes, R. DaSilva, M. Suéry, T. Bretheau. Effect of interfacial oxide layer in $\mathrm{Al}$ - SiC particle composites on bond strength and mechanical behaviour. Mat. Sci. Tech., 6 (7), 621-628 (1990).

11. D. J. Lloyd, P. L. Morris and E. Nehme. Tensile fracture of $6061 / 15 \% \quad \mathrm{Al}_{2} \mathrm{O}_{3}$ particulate. Fabrication of Particulate Reinforced Metal Composites, 17-19.09.1990, Montreal, Canada, 241-250 (1990).

12. S. B. Wu and R. J. Arsenault. The fracture mode in SiC / Al composites. Mat. Sci. Eng., A 138, 227235 (1991).

13. Y. Brechet, J. D. Embasy, S. Tao and L. Luo. Damage initiation in metal matrix composites. 
Acta Metall. Mater., 39 (8), 1781-1786 (1991).

14. P. N. Kalu and T. R. McNelly. Microstructural refinement by thermomechanical treatment of a cast and extruded $6061 \mathrm{Al}-\mathrm{Al}_{2} \mathrm{O}_{3}$ composite. Scr. Met. Mat., 25, 853-858 (1991).

15. J. H. Shyong, T.S. Shen and C.Y. Mo. The comprehension of microstructure and mechanical behaviour of casting and power processing of $\mathrm{SiC}_{\mathrm{p}}$ reinforced metal matrix composites. ICCM 10, Whistler, B.C. Canada, Aug. 1995, II, 409-416 (1995).

16. N. Kanetake, M. Nomura and T. Choh. Continuous observation of microstructural degradation during tensile loading of particle reinforced aluminium matrix composites. Mat. Sci. Tech., 11 (12), 12461252 (1995).

17. L. Sun, S. Li, Z. Zhu and Z.G. Wang. Dependence of fracture behaviour on $\mathrm{SiC}_{\mathrm{p}}$ size of $\mathrm{Al}$ matrix composites. ICCM 10, Whistler, B.C. Canada, Aug. 1995, $1295-300$ (1995).

18. D. L. Davidson. Fatique and fracture toughness of aluminium reinforced with $\mathrm{SiC}$ and alumina particles. Composites, 24, 248-255 (1993).

19. X. F. Hu. Some effect of particle size on the flow behaviour of $\mathrm{Al} / \mathrm{SiC}_{\mathrm{p}}$ Scr. Met. Mat., 25, 695-700 (1991).

20. F. Felli, A. Brotzu, F. Pinna and E. DiRusso. Structure and fatigue of an aluminium matrix composite obtained by indirect squeeze casting. Proc. Euromat 1995, Venice / Padua, Italy, 131136 (1995).

21. D.L. Davidson. The effect of particle shape and volume fraction on matrix deformation and fracture of Al composites. Proc. ASM, Oct. 1993, Pittsburgh Pennsylvania, 1895-1901 (1993).

22. J. Liu, D. Z. Wang, C. K. Yao, W. C. Yu and W. G. Wang. Effect of aging treatment on fatigue strength in $\mathrm{a} \mathrm{SiC}_{\mathrm{w}} / 6061 \mathrm{Al}$ composite. J. Mat. Sci., Let. 11, 970-972 (1992).

23. P. Gondi, R. Montanari and A. Sili. Mechanical properties and structural evolution of $\mathrm{Al}-\mathrm{Si}$ composites after aging treatment. Proc. Euromat 1995, Venice / Padua, Italy, 415-418 (1995).

24. C. S. Lee, J. H. Kim, T. Lim and K. S. Han. Dynamic observation of failure process in $\mathrm{Al} /$ $\mathrm{SiC}_{\mathrm{w}}$ composite. Scr. Met. Mat., 25, 613-618
(1991).

25. G.A.Rozak, J.J. Lewandowski and F. Wallace. Effects of casting conditions and deformation processing of A356 and A356-20vol $\mathrm{SiC}$ composites. J. Comp. Mat., 26 (14), 2076-2108 (1992).

26. G. Bao, J.W. Hutchinson and R.M. McMeeking. Particulate reinforced of ductile matrices again plastic flow and creep. Acta Metall Mater, 39 (8), 1871-1882 (1991).

27. Y. H. Teng and J.D. Boyd. Measurement of interface strength in $\mathrm{Al} / \mathrm{SiC}$ particulate composites. Composites, 25 (10), 906-912 (1994).

28. X. Xia and H.J. McQueen. Crack propagation and macrostructure in hot tension and cold bending particulate aluminium matrix composites. Proc. ICCM 10, Whistler, B.C. Canada, Aug. 1995, I 233-237 (1995).

29. S. V. Kamat, A. D. Rollet and J. R. Hirth. Plastic deformation in Al-alloy matrix-alumina particulate composites. Scr. Met. Mat., 25, 27-32 (1991).

30. A. Plumtree and P. Mummery. Accumulation of damage in Al MMCs. Proc. ICCM 10, Whistler, B.C. Canada, Aug. 1995, Il 257-262 (1995).

31. L. Ceschini, G.L. Garognani and G. Poli. Tensile test of $\mathrm{Al}_{2} \mathrm{O}_{3}$ particle reinforced $\mathrm{Al} 2014$ aluminium alloy at temperature from 25 to $200^{\circ} \mathrm{C}$. Proc. Euromat 1995, Venice / Padua, Italy, 427430 (1995).

32. N. Burgeois, K. Derrien and D. Baptiste. Observation and modelling of damage evolution in particulate reinforced MMCs. Proc. ICCM 10, Whistler, B.C. Canada, Aug. 1995, II 241-248 (1995).

33. I. Severin, G. Zgură and I. Marinescu. Al / SiC composites behaviour during thermomechanical processing. J. Sci. Eng. Comp. Mat., 6 (2), 77-84 (1997).

34. L. Salvo, M. Suery, D. Towle and C. M. Friend. Age hardening behaviour of liquid processed 6061 alloy reinforced with particulate and short fibers. Composites 27A, 1201-1210 (1996).

35. K. H. W. Seah, S. C. Sharma and B. M. Girish. Mechanical properties of as-cast and heat treated ZA-27/graphite particulate composites. Composiles 28A, 251-256 (1997). 
36. M. Manoharan and M. Gupta. Effect of variation in matrix constitution on the work hardening behaviour of a peak age hardened $\mathrm{SiC}$ reinforced aluminium based metal-matrix composites. Mat. Man. Proc., 13 (1), 53-64 (1998).

37. Z. M. El-Bradie and A. N. Abd El-Azim. Aging behaviour of aluminium alloy-glass particulate composite. J. Mat. Proc. Tech., 66, 73-75 (1997).

38. M. Gupta, S. Qiu and L. W. Chiu. Effect of particulate type on the microstructure and heattreatment response of $\mathrm{Al}-\mathrm{Cu}$ based metal matrix composites. J. Mat. Proc. Tech. 65, 245-251
(1997).

39. A. N. Abdel-Azim, Y. Shash, S. F. Mostafa and A. Younan. Aging behaviour of 2024Al alloy reinforced with $\mathrm{Al}_{2} \mathrm{O}_{3}$ particles. J. Mat. Proc. Tech., 55, 140-145 (1995).

40. M. Suery and L. Salvo. Matrix-reinforcement interactions during fabrication and thermal treatment of cast Al matrix composites. Met. New Mat. Res., III (3), 119-137 (1995).

41. P. Hartley, I. Pillinger and C. Sturgess. Numerical Modelling of Material Deformation Process. Springer Verlag London Lim. (1992). 